\begin{tabular}{c} 
Volume and Issues Obtainable at Center for Sustainability Research and Consultancy \\
Journal of Business and Social Review in Emerging Economies \\
ISSN: 2519-089X (E): 2519-0326 \\
Volume 3: Issue 2December 2017 \\
CSRᄃ \\
Journal homepage: $\underline{\text { www.publishing.globalcsrc.org/jbsee }}$ \\
\hline
\end{tabular}

\title{
Organization Citizenship Behavior: Notion of Social Exchange Theory
}

\author{
${ }^{1}$ Malka Liaquat, ${ }^{2}$ Khawaja Khalid Mehmood \\ ${ }^{1}$ Lecturer, Management Science Department, National University of Modern Languages, Multan, Pakistan \\ mliaqat@numl.edu.pk \\ ${ }^{2}$ Assistant Professor, Institute of Management Sciences, Bahauddin Zakariya University, Multan, Pakistan \\ khawjakhalid@bzu.edu.pk
}

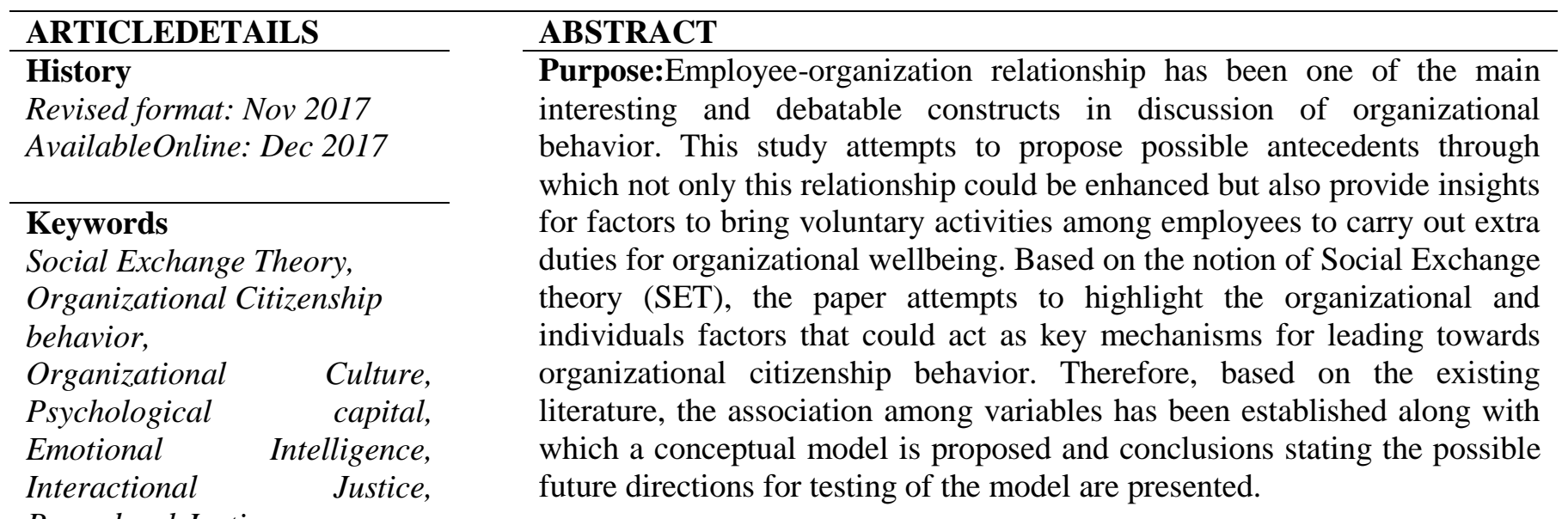

JEL Classification:

O24, O29, D23

(C) 2017 The authors, under a Creative Commons Attribution-

NonCommercial 4.00

Corresponding author's email address: khawjakhalid@bzu.edu.pk

Recommended citation:Liaquat,M.\& Mehmood,K.K., (2017).Organization Citizenship Behavior: Notion of Social Exchange Theory. Journal of Business and Social Review in Emerging Economies, 3(2) 209-216.

DOI:https://doi.org/10.26710/jbsee.v3i2.137

\section{Introduction}

Studies have been conducted in the arena of organizational behavior to identify processes and practices for enhancing organizational methods which helps in conducting smooth operations of organization's functioning. To overcome various organizational conflicts, managers and organizations are always seeking for solutions and theoretical underpinnings. Thus, to address such inconsistencies various theories have been developed in the genre of organizational behavior.

Social Exchange theory (Blau, 1964) is one of the theoretical foundations which caters to address various organizational processes and aspects. SET highlights the proponent that a series of "interdependent" interactions take place which are contingent on actions. It emphasizes that these inter-reliant transactions result in high potential relationship. SET provides an underlying conception for various organizational 
phenomenon such as psychological contracts (Rousseau, 1995) leadership (Liden, Sparrowe, \& Wayne, 1997), organizational justice (Konovsky, 2000), and other factors.

Among other theories, SET is one theory that provides a base for organizational citizenship behavior to explain employee organization exchange relationship. This study endeavors to identify the various antecedents that leads out towards organizational citizenship behavior along with the notion of social exchange theory as its base. As the practice of SET in context of organizational behavior is based on exchange principle, it accounts for the rule of reciprocity (Copanzano\& Mitchell, 2005). Thus, it leads to a consensus that employee relationship with organization is based on aspect of reciprocity and it is this exchange nature relationship which could determine the intrinsic or extrinsic behavior of an employee towards his organization.

Employees are one of the most important stakeholders of an organization as they play essential role in its success or failure. SET states that there exists exchange relationship among individuals, stating that an employee reciprocate in terms of its perception and performance with respect to treatment and information received from its organization.Similarly, when employees of an organization feel that their organization is involved in their wellbeing and socially responsible activities, then returns could be achieved from employees through their positive attitudes and extra role behaviors.

One of the critical determinants for promoting organizational effectiveness is "Culture" of an organization, often known as organizational Culture (Deal \& Kennedy, 1982; Ouchi\& Wilkins, 1985; Schein, 1990). Study of Wikhamn and Hall (2012) highlights that organizational culture acts as medium of exchange of beliefs, values and norms between the organization and employees. Further, study highlights that on the basis of mutuality notion, culture acts as strong medium for transferring organizational norms and values to its employee and in return shaping their perceptions and work performance outcomes. Therefore, this reciprocity helps in creation of mutual interdependence between employees and organization through communication of organizational norms and values in return shaping employees perception and extracting out work related outcomes.

Notion of SET enfolds its extension on the aspects of construct of organizational justice, stating if employees are provided a clear description of procedures, information and outcomes, this helps in enhancing employee performance and helps them in engaging positive work performance. Study conducted by Chen et al. (2015) provides evidence that exchange of accurate information helps to gain employees' trust and commitment. Thus, organizations providing a fair exchange on basis of outcomes, procedures, informational and interactional perspective lay downs a network of strong association, bondage, trust and loyalty on part of its employees.

To analyze how organizational exchanges through the facet of SET contributes towards leading out in workplace performance, Reis et al. (2007) explored the construct of emotional intelligence in this perspective of how exchanges between an employee and organizations takes place in the backdrop of SET. Thus, the study aimed to explore that ability of an individual to analyze changes taking place is strongly related to outcomes generated.

Notions of organizational citizenship behavior has been famous in various sectors such as banking (Chelagat, Chepkwony, \&Kemboi, 2015), telecommunication (Kashif, Khan, \& Rafi, 2011), and education (Gadot, 2007). One of an interesting area to study is health care. Health care sector has always been an area in focus and development in Pakistan, establishing new institutes and set-ups for the advancements of doctors. But an undermined area capturing attention in this current era is of 'nursing'. In the sector of health care, nursing is one of the unique and major work unit providing regular, consistent and superior health care quality to patients (Nayeri, Nazari, Salsali, \& Ahmadi, 2005).

Nursing in itself is an institute encompassing all structural and behavioral entities, entitled as important 
constituents of any organization. Besides the educational development of nursing, a concerning issue is behavioral aspect of nursing. It encompasses the different actions and outcomes as a result of HR practices. According to Kumar, Ahmed, Shaikh, Hafeez, and Hafeez (2013), human resources in an organization is one of the important components who act as a mechanisms of providing a valuable service network. Therefore, the lack of a sustainable service delivery creates question not only on the HR practices and policies but also on the institution itself. This raises a concern of the work routine and outcomes faced in nursing and performing of the extra role behaviors for organizations where prescribed duties create pressure is an important question to be addressed.

Based on the discussion generated, the scope of this study is to gap out, in context of social exchange theory, that how organizational culture, psychological capital and emotional intelligence influence an employee's organizational citizenship behavior in both terms as direct relationship and through interactional and procedural justice as mediators.

\section{Literature Review and Theoretical Relationship}

"Extra Role Behaviors" according to Organ (1988, p. 4), "are the discretionary behaviors of an individual which are not explicitly recognized by the formal reward system, and in the aggregate promote the efficient and effective functioning of the organization." Organizational Citizenship behavior is the umbrella term which addresses such behaviors. According to Schneider, Ehrhart, Mayer, Saltz, and NilesJolly (2005), OCB has always been valuable for organizations especially in facing the growing service imperatives. OCB entails with it numerous benefits for the organization such as, enhance efficiency, productivity and overcome turnover (Podsakoff, Whiting, Podsakoff, \& Blume, 2009).

Western countries highly promote organizational processes which incorporate OCB occurrences among its employees. In view of Pearce and Gregerson (1991), employees in the western world, such as in North America and Europe, are sure of the laws, rules, and legal rights of protections by the organizations which enforce their perception in promoting organizational image and repute, thus leading them to act in favor of the organization and which makes them more cognizant towards their organization.

Enormous studies have been laid down in western countries providing a stream of works which identify such processes that heighten extra effort behaviors among its employees. These are for instance, studies such as in Australia, on job satisfaction and OCB among human service workers (Murphy, Athanasou, \& King, 2002), individual characteristics of whistle blowers of organization on OCB (Kraemer, 2008) and workplace attitudes and its outcomes on OCB among hospital nurses (Cavanagh, Fisher, Francis, \&Gapp, 2012). In North America, there have been studies, for instance, regarding emotional exhaustion and OCB among nursing staff members (Halbesleban\& Bowler, 2007), and OCB with organizational commitment among knowledge workers (Öztürk, 2010).

The construct of OCB carries equal emphasis in eastern societies as well; the pioneering role is the work by Farh, Earley, and Lin (1997), identifying the Asian dimensions of OCB, and this has further been explored in Chinese and Taiwanese researches (Chen \&Francescco, 2003; Chu, Lee, \& Hsu, 2006; Liang, Ling, \& Hsieh, 2007). In Chinese society, an association and analogy has been established between culture and OCB perspectives.

In context of Pakistan, although being an eastern country caries the same cultural and ethnic perspectives, it is recognized as a country where values and beliefs act as strong base for association but in context of organizational perspective, there lies a gap between the organization and employees which leads towards phenomena of familistic collectivism. Studies have been in discussion for identifying various antecedents of OCB such as individual disposition (Kashif et al., 2011), job satisfaction (Yousaf\& Sanders, 2012), perceived organizational support (Khan,Mahmood, Kanwal, \& Latif, 2015). But an exploration of 
underlying processes governing and molding employee perceptions and attitudes envisaging OCB and how it could shape employees behavior to do more for the organization's well-being is still underemphasized.

The study aims to identify the various facets not only in direct relationships of organizational culture, but also determining the mediational effect of interactional justices and procedural justice to examine the extent to which variables acts in associations on employees for voluntary "extra efforts" to act as good soldiers of organization especially in scenario of nursing sector in Pakistani Context.

Mohanty andRath(2012), in a three sector study of manufacturing, information technology, and banking, highlight how culture stands as an important notion in shaping employee's behavior and attitudes. They further identified the characteristic of culture such as beliefs and norms, conflict and risk tolerance, structure, and individual responsibility that stand out in leading towards the altruistic, sportsmanship and consciousness in an employee's attitude towards its organization. According to a study conducted by Subramanian and Yen (2013), few of the various traits of organizational culture are regulatory and guidance aspect, in the very same way children are provided guidance and monitored by parents. Therefore, culture could be used as a strong facilitator in influencing and molding an employee's belief and can bring out the component of "extra effort" in their work outcomes.

One of outbranch of psychology and organizational behavior which is labeled positive extension is psychological capital (Luthans\& Youssef, 2004). According to Luthans and Youssef (2004), it is conceptualized as a mind's positive state revealed during the course of an individual's development and growth. Thus, an individual with strong sense of self-efficacy, optimism and challenge taking attitude has the ability to carry out the extra role behaviors for the organizational prospects and growth. Golestaneh (2014) focuses on the relationship between how psychological capital positively contributes towards citizenship behavior of an employee. Thus, an employee's hope, self-efficacy and sense of optimism contributes significantly in bringing out the "good soldier" syndrome in an employee.

Conception of emotional intelligence came out from the work of Salovey and Mayer (1990), classifying it as a trait of intelligence of social outset than general disposition. It is an ability to monitor not only one's own emotions, instead other persons' emotions and to differentiate and use it as guiding tool for shaping one's ideas. On the other hand, Turner (2004) classified it as "softer component" of whole intelligence which addresses both personal and professional lives of individuals. Therefore, an employee's emotional intelligence does contribute towards his actions and performance towards organization.

Human traits have been recognized as playing an important role in bringing out an individual's outcomes in workplace. Carmeli and Josman (2009) advocate this perspective in their article stating that higher level of work and task performance is positively related with individuals having high emotional intelligence. Thus, an individual with ability to monitor her emotions is in a better position to better understand the organizational stance and work in generating positive outcomes and performing extra efforts.

Literature in domain of organizational behavior provides evidence regarding interrelation between organizational justice and extra-role behaviors. Moliner, Martínez-Tur, Ramos, Peiró, and Cropanzano (2008), in their study extended this domain by studying justice with extra role behaviors of customer services, exploring the direct effects and indirect effects through burnout and engagement. Judgments about the fairness of the process of making decisions, empathy and apprehension act as strong ingredients for employees behaviors. Perception of being fairly rewarded and provided with equitable allocation of resources helps to create a sense of obligation in employees (Kalay, 2016). This obligation would lead towards performing extra roles for organization's betterment.

Taamneh (2015) tested that how interactional justice contributes towards the organizational citizenship behavior, by conducting analysis of sample of 98 employees and 20 managers to measure how the 
practice of interactional justice takes place in rooting the citizenship behavior among employees. Wang, Liu, Luo, Ma, and Liu (2016), in study conducted in China, for 212 subordinate and employee relationship in transportation group identified that procedural justice plays a significant role in an employee's work outcomes. Similarly, Zhang, Lee, and Zou (2012), in their study emphasized on the aspect that a clear description of action, decision making, and procedures when communicated to employees provides a support for organization in bringing out voluntary actions on part of its employees.

\section{Research Framework}

Research framework of proposed relationships in provided in figure 1, thus comprises of organizational culture, and psychological capital, and emotional intelligence as independent variables and organizational citizenship behavior as dependent variable, along with interactional justice and procedural justice playing the role of mediators. The model highlights direct and indirect relationship that exists between the independent, mediating and dependent variables.

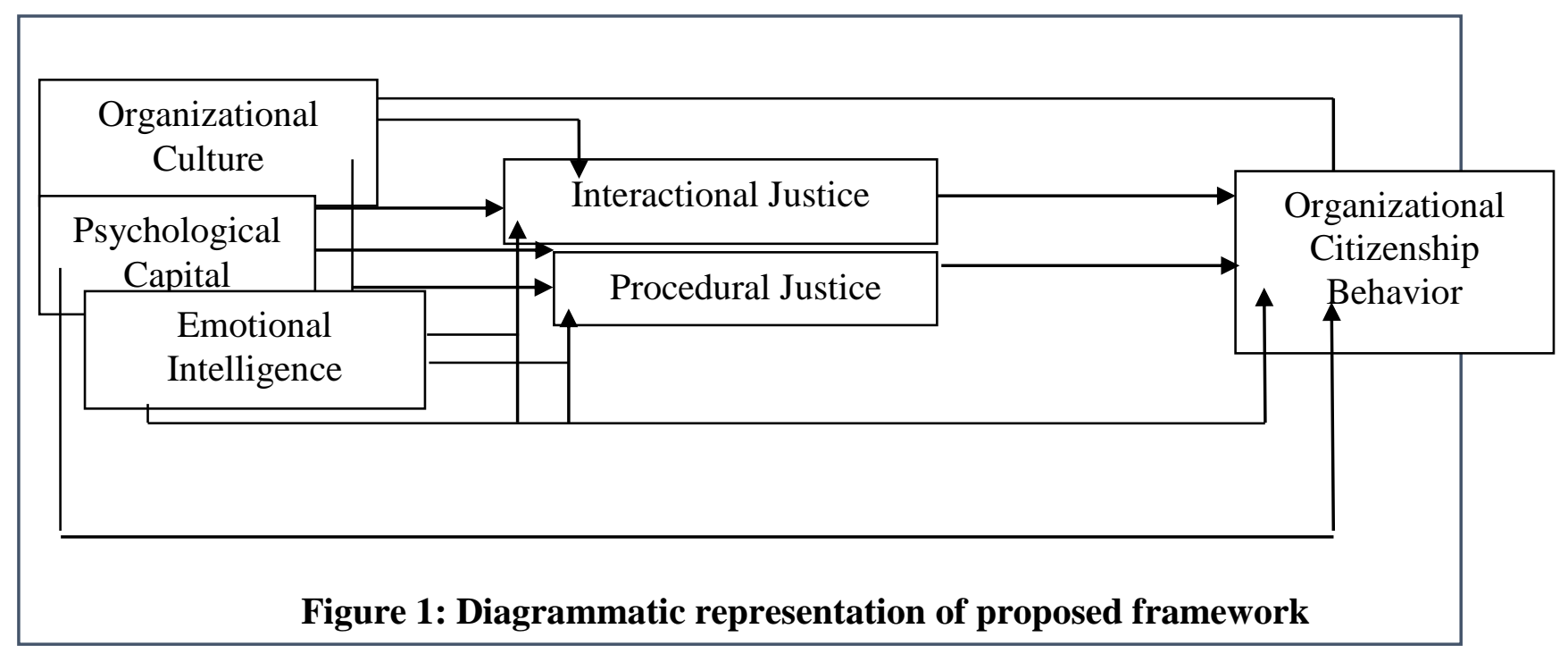

\section{Conclusion}

Prospect of enhancing an employee's attitude towards organizational tasks and responsibilities does depends upon the various organizational and individual indicators. An innate tendency is to be created on part of employees for performing more than the prescribed roles and characters assigned by organizations. There can be conflicts, confusions and disagreements on both parties i.e. organization and employee leading to breaking of a mutual agreement. Behavioral competency is what is required to overcome these issues and create a viable mutual benefit for both parties - one of the outcome notions of Social exchange theory.

The work presented in this paper contributes towards existing body of literature and provides an extension of social exchange theory. It allows an opportunity to test if social exchange theory in context of Pakistan acts as a base for organizational citizenship behavior or any specific cultural traits effects it applicability. In this paper, a conceptual model is proposed for enhancing employees' voluntary actions and efforts towards organization. This paper does not suffice only on a specific process rather accounts both organizational and individual approaches for creating a more proactive approach towards efforts rather than the reactive actions.

\section{References}

Blau, P. (1964). Power and exchange in social life. NY: John Wiley \& Sons.

Carmeli, A., \&Josman, Z. E. (2009).The relationship among emotional intelligence, task performance, and organizational citizenship behaviors.Human performance, 19(4).403-419. 
Cavanagh, J., Fisher, R., Francis, M., \&Gapp, R. (2012).Linking nurses' attitudes and behaviors to organizational values: Implications for human resource management.Journal of Management \& Organization, 18(05), 673-684.

Chelagat, L., Chepkwony, P. K., \&Kemboi, A. (2015).Effect of organizational citizenship behavior on employee performance in banking sector, Nairobi County, Kenya.International Journal of Business, Humanities and Technology, 5(4), 55-61.

Chen, Z. X., \& Francesco, A. M. (2003).The relationship between the three components of commitment and employee performance in China.Journal ofVocational Behavior, 62(3), 490-510.

Chen, S. Y., Wu, W. C., Chang, C. S., Lin, C. T., Kung, J. Y., Weng, H. C., ... \& Lee, S. I. (2015). Organizational justice, trust, and identification and their effects on organizational commitment in hospital nursing staff.BMC Health Services Research, 15(1), 1-17.

Chu, C. I., Lee, M. S., \& Hsu, H. M. (2006).The impact of social support and job stress on public health nurses' organizational citizenship behaviors in rural Taiwan.Public Health Nursing, 23(6), 496505.

Copanzano, R., \& Mitchell, M. S. (2005). Social exchange theory: An interdisciplinary review. Journal of Management,31(6).874-900.

Deal, T., \& Kennedy, A. (1982). Corporate cultures. Reading, MA: Addison-Wesley

Farh, J.-L., Earley, P. C., \& Lin, S.-C. (1997). Impetus for action: A cultural analysis of justice and organizational citizenship behaviour in Chinese society.Administrative Science Quarterly, 42, 421-444

Gadot, V. E. (2007). Redrawing the boundaries of OCB? An empirical examination of compulsory extrarole behavior in the workplace.Journal of Business and Psychology, 21(3), 377-405.

Golestaneh, S. M. (2014). The relationship between psychological capital and organizational citizenship behavior.Management and Administrative Sciences Review, 3(7), 1165-1173.

Halbesleben, J. R., \& Bowler, W. M. (2007). Emotional exhaustion and job performance: The mediating role of motivation. Journal of Applied Psychology, 92(1), 93-106.

Kalay, F. (2016). The impact of organizational justice on employee performance: A survey in Turkey and Turkish context. International Journal of Human Resource Studies, 6(1), 1-20

Kashif, M., Khan, Y., \& Rafi, M. (2011).An exploration of the determinants of OCB in the telecommunication sector of Pakistan.Asian journal of Business Management, 3(2), 91-97.

Khan, S. I., Mahmood, A., Kanwal, S., \& Latif, Y. (2015). How perceived supervisor support effects workplace deviance? Mediating role of perceived organizational support.Pakistan Journal of Commerce and Social Sciences, 9(3), 940-967.

Konovsky, M. A. (2000). Understanding procedural justice and its impact on business organizations.Journal of Management, 26(3), 489-513.

Kraemer, S. (2008).The whistleblower in the workplace: The influence of the personal characteristics of individuals who have blown the whistle in one Australian context. Retrieved from http://ro.ecu.edu.au/theses/229 (Retrieved on February 27, 2017)

Kumar, R., Ahmed, J., Shaikh, B. T., Hafeez, R., \&Hafeez, A. (2013). Job satisfaction among public health professionals working in public sector: A cross sectional study from Pakistan. Human Resources for Health, 11(2), 1-5.

Liden, R. C., Sparrowe, R. T., \& Wayne, S. J. (1997). Leader-member exchange theory: The past and potential for the future. Research in personnel and human resources management, 15, 47-120.

Liang, S. K., Ling, H. C., \& Hsieh, S. Y. (2007). The mediating effects of leader-member exchange quality to influence the relationships between paternalistic leadership and organizational citizenship behaviors. Journal of American Academy of Business, 10(2), 127-137.

Luthans, F., \& Youssef, C. M. (2004). Human, social, and now positive psychological capital management: Investing in people for competitive advantage. Organizational Dynamics, 33, 143160.

Mohanty, J., \&Rath, B. P. (2012). Influence of organizational culture on organizational citizenship behavior: A three-sector study. Global Journal of Business Research, 6(1), 65-76. 
Moliner, C., Martínez-Tur, V., Ramos, J., Peiró, J., \&Cropanzano, J. (2008). Organizational justice and extrarole customer service: The mediating role of well-being at work. European Journal of Work and Organizational Psychology, 17(3), 327-348.

Murphy, G., Athanasou, J., \& King, N. (2002). Job satisfaction and organizational citizenship behaviour: A study of Australian human-service professionals. Journal of Managerial Psychology, 17(4), 287-297.

Nayeri, N, D., Nazari A, A., Salsali, M., \& Ahmadi, F. (2005). Iranian staff nurses' views of their productivity and human resource factors improving and impeding it: A qualitative study. Human Resources for Health, 3(9), 1-11.

Organ, D. (1988).Organizational citizenship behavior: The good soldier syndrome. Virginia: Lexington Books.

Ouchi, W., \& Wilkins, A. (1985).Organizational culture.In R. Turner (Ed.), Annual review of sociology, 11,457-483. Palo Alto, CA: Annual Reviews

Öztürk, F. (2010).Determinants of organizational citizenship behavior among knowledge workers: The role of job characteristics, job satisfaction, and organizational commitment (Unpublished Doctoral dissertation), Middle East Technical University, Turkey.

Pearce, J., \&Gregersen, H. (1991). Task interdependence and extra role behavior: A test of the mediating effects of felt responsibility. Journal of Applied Psychology, 76(6), 838-844.

Podsakoff, N. P., Whiting, S. W., Podsakoff, P. M., \& Blume, B. D. (2009). Individual-and organizational-level consequences of organizational citizenship behaviors: A meta-analysis. Journal of Applied Psychology, 94(1), 122-141.

Reis, D. L. et al. (2007). Emotional intelligence predicts individual differences in social exchange reasoning. NeuroImage, 35(3), 1385-1391.

Rousseau, D. M. (1995).Psychological contracts in organizations: Understanding written and unwritten agreements. CA: Sage

Salovey, P., \& Mayer, J. (1990).Emotional intelligence.Imagination, cognition, and personality, 9(3), 185-211.

Schein, E. (1990). Organizational culture.AmericanPsychologist, 45(2), 109-119.

Schneider, B., Ehrhart, M. G., Mayer, D. M., Saltz, J. L., \& Niles-Jolly, K. (2005). Understanding organization-customer links in service settings. Academy of Management Journal, 48(6), 10171032 .

Subramanian, I. D., \& Yen, C. L. (2013). Emotional intelligence of leaders and organizational evidence from IT companies in Malaysia. Journal of Business Management, 7(11), 882-890.

Taamneh, A. (2015). The impact of practicing interactional justice on employees organizational citizenship behavior (OCB) in the Jordanian ministry of justice. European Journal of Business and Management, 7(8).170-180.

Turner, L. (2004). Emotional intelligence --- Our intangible asset?Chartered Accountants Journal of New Zealand, 83(3), 29-31.

Wang, H., Liu, X., Luo, H., Ma, B., \& Liu, S. (2016). Linking procedural justice with employees work outcomes in China: The mediating role of job security.Social Indicators Research, 125(1), 77-88.

Wikhamn, W., \& Hall, A. T. (2012).Social exchange in a Swedish work environment.International Journal of Business and Social Science, 3(23), 56-64.

Yousaf, A., \& Sanders, K. (2012). The role of job satisfaction and self-efficacy as mediating mechanisms in the employability and affective organizational commitment relationship: A case from a Pakistani university. Thunderbird International Business Review, 54(6), 907-919.

Zhang, G., Lee, G., \& Zou, X. (2010).The mediating role of procedural justice between participation in decision-making and organizational citizenship behavior: An empirical study about Skeleton Government Civilian in China. Psychology, 1(4), 300-304. 
